\title{
Prevalence of Stunting among Children Aged 6 to 36 Months, in the Eastern Province of Sri Lanka
}

\section{Sujendran $\mathbf{S}^{1 *}$, Senarath $\mathrm{U}^{2}$ and Joseph $\mathrm{J}^{1}$}

${ }^{1}$ Department of Supplementary Health Sciences, Faculty of Health-Care Sciences, Eastern University, Sri Lanka ${ }^{2}$ Department of Community Medicine, Faculty of Medicine, University of Colombo, Sri Lanka

\begin{abstract}
Objective: This study aims to assess the prevalence of stunting among children aged 6-36 months and to describe the underlying factors and feeding practices of infants and young children in 2 districts of the Eastern Province in Sri Lanka.

Methodology: A cross-sectional quantitative survey was conducted in Batticaloa and Kalmunai health districts of the Eastern Province in Sri Lanka from July to December 2013. A sample of 1400 children was identified using a stratified cluster sampling method, and the data were obtained from mothers or care givers using an interviewer administered questionnaire. Anthropometric measurements were taken using standard procedure and equipment. Stunting was defined as the proportion of children whose height-for-age $Z$ score was less than -2 according to WHO growth standards.

Results: The prevalence of stunting was $16.8 \%(95 \% \mathrm{Cl} ; 14.1,18.0)$ among the children aged 6-36 months, in the Eastern Province of Sri Lanka. The prevalence of wasting was $21.5 \%(95 \% \mathrm{Cl} ; 18.8,24.3)$, and underweight was $27.2 \%(95 \% \mathrm{Cl} ; 19.8,28.7)$ in this age group. Boys were more stunted $(20.3 \%(95 \% \mathrm{Cl} ; 16.1,24.2))$ than girls $(14.0 \%(95 \% \mathrm{Cl} ; 9.6$ and 16.5$))$. Underlying factors include: lower educational level of parents $(\mathrm{OR}=4.91, \mathrm{p}=0.048)$; lower family income $(O R=1.48, p=0.011)$; low birth weight $(O R=1.28, p=0.049)$; exclusive breastfeeding period less than 6 months $(O R=2.29, p=0.041)$; poor complementary feeding practices $(O R=1.51, p=0.048)$; irregular clinic visits $(O R=1.52, p=0.041)$ and not getting advice from health personnel $(O R=1.41, p=0.041)$.

Conclusion: Prevalence of stunting among children aged 6-36 months in the Eastern Province is higher than the rest of the country. Poor infant and young child feeding practices was identified as one of the modifiable factors. Breastfeeding and the complementary feeding practices need improvement through improved feeding behavior of mothers and/or care givers.
\end{abstract}

Keywords: Stunting; Infant and young feeding; Nutrition counseling; Undernutrition

\section{Introduction}

Good nutrition means "maintaining a nutritional status that enables us to grow well and enjoy good health" [1]. Malnutrition can be defined as the insufficient, excessive or imbalanced consumption of nutrients. It is a complex and multisectoral issue that involves a wide spectrum of causes at individual, household, and community level. According to the World Health Organization (WHO), childhood malnutrition is the gravest single threat to global public health [2]. Childhood undernutrition may have long-term consequences including impairment in physical, cognitive, and psychosocial performance, and those children with severe Undernutrition typically experience slow behavioral development, and even mental retardation [3-5]. The Lancet series on maternal and child undernutrion in 2008 has highlighted the gravity of problem in terms of mortality and overall disease burden due to nutrition related causes [6]. According to this series, stunting, severe wasting, and intrauterine growth restriction together were responsible for 2.2 million deaths and $21 \%$ of disability-adjusted lifeyears (DALYs) for children younger than 5 years, and that constitutes the largest percentage of any risk factor in this age group. Satisfactory growth at young age is extremely important as it determines the future growth and development.

Inadequate linear growth is a manifestation of long term protein and energy insufficiency and referred to as stunting or chronic malnutrition. It reflects achieved linear growth and indicates long-term, cumulative inadequacies of health or nutrition (WHO, 2005). Stunting is defined as height for age less than $-2 \mathrm{Z}$ score of the reference population. For children below 2 years of age, the term length-for-age is used. According to the new international growth standards, $32 \%$ of children less than 5 years of age were stunted (height-for-age $Z$ score less than -2), 10\% wasted (weight-for-height $Z$ score less than -2) and 20\% underweight (weight-for-age $Z$ score less than -2) in the developing world [1]. In Sri Lanka, malnutrition among children due to nutritional deficiency remains a significant public health problem despite its remarkable achievements in maternal and child mortality indicators. The Sri Lanka Demographic Health Survey (DHS) conducted in 2006/07 revealed that $17.3 \%$ of the under-five year children were stunted, $14.7 \%$ wasted and $21.2 \%$ underweight [3]. The Nutrition and Food Security Survey 2009 (NFSS 09) in Sri Lanka reported a marginal increase in stunting, with its prevalence being $19.2 \%$ in the same age group [4]. The trends of health and nutritional indicators in Sri Lanka during the past decade reveal that the rates of stunting and underweight remain static, while a marginal decline in wasting, despite improved many other health indicators [3-5].

The conceptual framework developed by UNICEF explains the

${ }^{*}$ Corresponding author: Sujendran S, Department of Supplementary Health Sciences, Faculty of Health-Care Sciences, Eastern University, Sri Lanka, Tel: +94714866181; Fax: +94652222059; E-mail: sankarapillaisujendran@gmail.com

Received January 18, 2015; Accepted February 24, 2015; Published February 28, 2015

Citation: Sujendran S, Senarath U, Joseph J (2015) Prevalence of Stunting among Children Aged 6 to 36 Months, in the Eastern Province of Sri Lanka. J Nutr Disorders Ther 5: 154. doi:10.4172/2161- 0509.1000154

Copyright: @ 2015 Sujendran S, et al. This is an open-access article distributed under the terms of the Creative Commons Attribution License, which permits unrestricted use, distribution, and reproduction in any medium, provided the original author and source are credited. 
causes of child malnutrition at three levels: immediate; underlying and basic [7]. Inadequate dietary intake and disease are immediate causes whereas household food insecurity, lack of care for mothers and children, and inadequate health services and adverse environmental conditions are hypothesized as the underlying causes $[7,8]$. The basic causes include economic and political structure, socio-cultural context and potential resources. Globally, poor breastfeeding and complementary feeding practices, coupled with high rates of infectious diseases, are the principal proximate causes of malnutrition during the first two years of life $[8,9]$. In addition, there were inherent determinants such as age and sex of the child, birth weight and maternal height [10-13]. A causal analysis using the data from Sri Lanka DHS in 2000 concluded that the most significant predictor of underweight, wasting and stunting in children under 5 years of age was low birth weight [14]. This study also revealed that poor socio-economic status and substandard antenatal care were strong predictors of undernutrition. In contrast to global findings, undernutrion was not associated with occurrence of diarrhea or respiratory infections in Sri Lanka [14]. The aim of the present study is to assess the prevalence of stunting in children aged 6-36 months, and to describe the immediate, underlying and basic factors that are predictive of stunting in the Eastern Province in Sri Lanka. The knowledge on these predictors could be useful in informing the health and nutrition policies and programmes to focus on strategies to minimize these predictors.

\section{Methodology}

\section{Design and sample}

A cross-sectional descriptive study was conducted in two health districts in the Eastern Province, namely Batticaloa and Kalmunai, from July to December 2013. The total midyear populations of these 2 districts for year 2013 were 579,489 and 415,698 respectively. The study population comprised of children aged 6 to 36 months, and their mothers or care givers. A stratified cluster sampling was carried out to select the participants. The two health districts were considered as strata and the Public Health Midwife (PHM) areas as clusters. The sample size was calculated to estimate the prevalence of stunting to be $20 \%$ with its $95 \%$ confidence intervals within 3\% precision. Sample size was generated using a statistical formula described by Donner and Klar (2000)15 (refer Annex 1). Further, this sample was multiplied by a design effect of 2 to adjust for the clustering effect, considering a cluster size of 40 children and the Intra-cluster correlation coefficient (ICC) of 0.02 for stunting. The final sample size was 1400 children, and the number of clusters was 35 . The 35 clusters (PHM areas) were randomly selected from the two health districts proportionate to the population size in each health district. A sample of forty participants from each PHM area was identified from the households which were geographically close by.

\section{Instruments}

Six field assistants were trained on interviewing mothers/care givers and taking anthropometric measurements in children. Two calibrated standard electronic weighing scales of 'Seca' brand ( $\mathrm{d}=100 \mathrm{~g}, \mathrm{Max}=$ $150 \mathrm{~kg}, \mathrm{Min}=2 \mathrm{~kg}$ ) were used to weigh the children. Length / height of the children were measured using two 'ADE' brand measuring boards $(0-200 \mathrm{~cm})$. The same instruments were used by the field assistants throughout the study in order to nullify possible measurement bias. An interviewer administered questionnaire was developed by the investigators and pre-tested in a similar setting. The questionnaire consisted of following sections: characteristics of mother/care giver; antenatal history of mother; characteristics of the child; recent health history; breast feeding; complementary feeding; food habits; cultural and religious beliefs; and a 24 hour dietary recall. The principle investigator supervised the data collection process throughout this period.

\section{Analysis and interpretation}

Data were analyzed using Statistical Package for Social Science (SPSS evaluation version) and WHO anthro (v3.22) software. The associations between the outcome and predictors of stunting were assessed using Odds Ratio (OR) and p-values.

\section{Ethical considerations}

Informed written consent was obtained from all participants. The participants were also informed about their right to withdraw at any stage of the study. All data records were kept safe and secure. Measures were taken to safeguard confidentiality, anonymity and the psychological wellbeing of participants. Ethics Review committee of the Faculty of Health-Care Sciences, Eastern University of Sri Lanka has granted ethics clearance for this study.

\section{Results}

Of the 1400 children, 760 (54.3\%) were from Batticaloa and 640 (45.7\%) were from Kalmunai. The proportions of males and females were $51.4 \%$ and $48.6 \%$ respectively. Figure 1 shows the distribution of length-for-age $\mathrm{Z}$ scores in the sample in comparison to the lengthfor-age $\mathrm{Z}$ scores of the WHO reference population. Data from the present study shows somewhat asymmetrical and positively skewed distribution. The curve has shifted towards left in comparison to the WHO length-for-age $\mathrm{Z}$ scores curve for the same age group. The mean is closer to $-2 Z$ of the reference population, and the majority of children have length-for-age $\mathrm{Z}$ scores below 0 .

The prevalence of stunting (percentage below $-2 \mathrm{Z}$ score) was $16.8 \%(95 \% \mathrm{CI} ; 14.1,18.0)$ and that of wasting and underweight were $21.5 \%$ (95\% CI; $18.8,24.3$ ), and $27.2 \%$ ( $95 \%$ CI; 19.8, 28.7) respectively, among children aged 6-36 months. Among the children aged 6-11 months, the percentage of acute undernutrition (wasting) was $23.2 \%$. This is $11.2 \%$ higher than the average. Similarly, the children belong to the age groups 12-23 and 24-36 months were more stunted in comparison with other age groups (Table 1).

There were more stunted boys $(20.3 \%, 95 \% \mathrm{CI} ; 16.1,24.2)$ than girls $(14.0 \%, 95 \% \mathrm{CI} ; 9.6,16.5)$. Girls were stunted more during their third year of age $(26.1 \%, 95 \%$ CI; $12.5,41.5)$ compared to boys $(24.3 \%, 95 \%$ CI; 10.9, 30.1) (Table 2).

Table 3 describes the food consumption patterns of the 1400 children and their families. Food habits analysis shows inadequate intake of animal protein in most of the families. About $38 \%$ of the participants never consume beef or mutton, while $12.4 \%$ never eat sea foods. Of the children, $12.6 \%$ eat chicken daily and $12.9 \%$ consume fresh water fish daily. Very few children consume green leafy vegetables, fruits and other vegetable regularly. The dietary diversity of food consumed among the children was poor (Table 3 ).

Approximately $67 \%$ of mothers had an education level of below the secondary school having a strong association with wasting below $-2 \mathrm{SD}$ with a $\mathrm{p}$ value 0.011 and an odds ratio of 6.89 . Similarly, low birth weight, poor complementary feeding practices and the period of exclusive breast feeding and many other predictors are having strong associations with stunting (Table 4).

According to cross-tabulations, there was an association between 
Citation: Sujendran S, Senarath U, Joseph J (2015) Prevalence of Stunting among Children Aged 6 to 36 Months, in the Eastern Province of Sri Lanka. J Nutr Disorders Ther 5: 154. doi:10.4172/2161- 0509.1000154

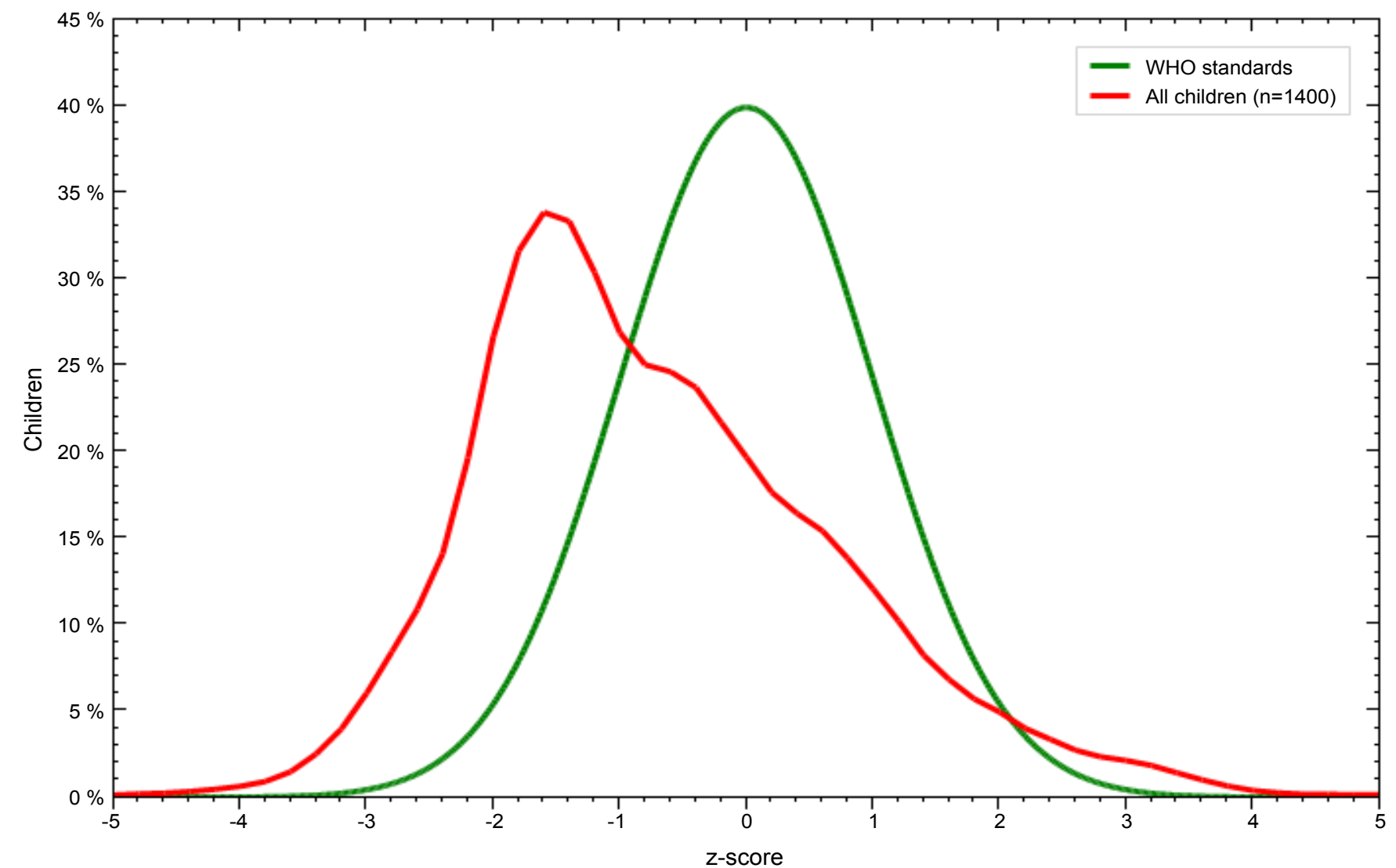

Figure 1: Distribution of Stunting (height/length-for-age Z score) among Children Aged 6-36 Months, In Eastern Province, Sri Lanka ( $\mathrm{n}=1400$ ).

\begin{tabular}{|c|c|c|c|}
\hline Type of under nutrition (below -2SD) & Age Group & Eastern Province $(n=1400)$ & Sri Lanka (Source: *NNMS2012) \\
\hline \multirow{4}{*}{ Stunting (Height -for -age) } & $6-36$ months & $16.8 \%(95 \% \mathrm{Cl} ; 14.1,18.0)$ & $13.15 \%$ \\
\hline & 6-11 months & $14 \%$ & $8.3 \%$ \\
\hline & $12-23$ months & $18 \%$ & $16.9 \%$ \\
\hline & 24-36 months & $25.2 \%$ & $15.2 \%$ \\
\hline \multirow{4}{*}{ Wasting (Weight-for height) } & 6-36 months & $21.5 \%(95 \% \mathrm{Cl} ; 18.8,24.3)$ & $19.6 \%$ \\
\hline & 6-11 months & $23.2 \%$ & $12.5 \%$ \\
\hline & $12-23$ months & $20.2 \%$ & $18.8 \%$ \\
\hline & 24-36 months & $19.1 \%$ & $22.2 \%$ \\
\hline \multirow{4}{*}{ Underweight (Weight-for -age ) } & 6-36 months & $27.2 \%(95 \% \mathrm{Cl} ; 19.8,28.7)$ & $23.5 \%$ \\
\hline & 6-11 months & $27.8 \%$ & $14.1 \%$ \\
\hline & $12-23$ months & $25.8 \%$ & $25.6 \%$ \\
\hline & 24-36 months & $29.7 \%$ & $27.7 \%$ \\
\hline
\end{tabular}

*NNMS - National Nutrition and Micronutrient Survey 2012

Table 1: Prevalence of Stunting, Wasting and Underweight among the Children.

\begin{tabular}{|c|c|c|c|c|c|c|c|c|c|c|}
\hline \multirow{2}{*}{$\begin{array}{l}\text { Age Group (in } \\
\text { months) }\end{array}$} & \multicolumn{5}{|c|}{ Boys } & \multicolumn{5}{|c|}{ Girls } \\
\hline & Stunting (below -2SD) & $95 \% \mathrm{Cl}$ & Mean & SD & No of children & Stunting (below -2SD) & $95 \% \mathrm{Cl}$ & Mean & SD & No of children \\
\hline $6-36$ & $20.3 \%$ & $16.1,24.2$ & -0.79 & 1.38 & 720 & $14.0 \%$ & $9.6,16.5$ & -0.62 & 1.44 & 680 \\
\hline $6-11$ & $18.1 \%$ & $12.3,23.8$ & -0.65 & 1.42 & 349 & $10.1 \%$ & $6.0,14.4$ & -0.63 & 1.40 & 348 \\
\hline $12-23$ & $21.9 \%$ & $15.0,28.6$ & -0.83 & 1.39 & 293 & $13.7 \%$ & $7.8,19.6$ & -0.46 & 1.53 & 263 \\
\hline $24-36$ & $24.3 \%$ & $10.9,30.1$ & -1.24 & 1.11 & 78 & $26.1 \%$ & $12.5,41.5$ & -1.15 & 1.44 & 69 \\
\hline
\end{tabular}

Table 2: Comparison of stunting between boys and girls boys aged 6-36 months in eastern Province, Sri Lanka $(n=1400)$.

young mothers aged below 22 years and stunting $(\mathrm{OR}=1.87 ; \mathrm{P}$ value $0.38)$. Poor family income $(\mathrm{OR}=1.48 ; \mathrm{P}$ value 0.011$)$ and nuclear type family (OR=1.11; P value 0.042) contribute much towards stunting of the children in the region. Similarly, antenatal care of the mother including nutritional supplementation $(\mathrm{OR}=1.71 ; \mathrm{P}$ value 0.015$)$ and worm treatment $(\mathrm{OR}=2.56$; $\mathrm{P}$ value 0.010$)$ have positive association 


\begin{tabular}{|c|c|c|c|c|c|c|c|c|c|c|c|}
\hline \multirow{2}{*}{\multicolumn{2}{|c|}{ *Food consuming pattern }} & \multicolumn{2}{|c|}{ Never } & \multicolumn{2}{|c|}{ Once a month } & \multicolumn{2}{|c|}{ Once a week } & \multicolumn{2}{|c|}{ Twice a week } & \multicolumn{2}{|c|}{ Daily } \\
\hline & & \multirow{2}{*}{$\begin{array}{c}\text { No of children } \\
174\end{array}$} & \multirow{2}{*}{$\begin{array}{c}\% \\
12.4\end{array}$} & \multirow{2}{*}{$\begin{array}{c}\begin{array}{c}\text { No of } \\
\text { children }\end{array} \\
486\end{array}$} & \multirow{2}{*}{$\begin{array}{c}\% \\
34.7\end{array}$} & \multirow{2}{*}{$\begin{array}{c}\begin{array}{c}\text { No of } \\
\text { children }\end{array} \\
740\end{array}$} & \multirow{2}{*}{$\begin{array}{c}\% \\
52.8\end{array}$} & \multirow{2}{*}{$\begin{array}{c}\begin{array}{c}\text { No of } \\
\text { children }\end{array} \\
-\end{array}$} & \multirow{2}{*}{$\begin{array}{l}\% \\
-\end{array}$} & \multirow{2}{*}{$\begin{array}{c}\begin{array}{c}\text { No of } \\
\text { children }\end{array} \\
-\end{array}$} & \multirow{2}{*}{$\begin{array}{c}\% \\
-\end{array}$} \\
\hline 1 & S. Food & & & & & & & & & & \\
\hline 2 & F. W. Fish & - & - & 1 & 0.1 & 444 & 31.7 & 775 & 55.4 & 180 & 12.9 \\
\hline 3 & Bf/ Mut. & 531 & 37.9 & 675 & 48.2 & 194 & 13.9 & - & - & - & - \\
\hline 4 & Chicken & 3 & 0.2 & 16 & 1.1 & 439 & 31.4 & 765 & 54.6 & 177 & 12.6 \\
\hline 5 & Eggs & - & - & 63 & 4.5 & 1027 & 73.4 & 238 & 17 & 72 & 5.1 \\
\hline 6 & Leg. /Puls & - & - & 206 & 14.7 & 455 & 32.6 & 588 & 42 & 151 & 10.8 \\
\hline 7 & Fruits & - & - & - & - & 76 & 5.4 & 404 & 28.9 & 920 & 65.7 \\
\hline 8 & G.L. Veg. & - & - & - & - & 679 & 48.5 & 559 & 39.9 & 162 & 11.6 \\
\hline 9 & Milk & 150 & 10.7 & 351 & 25.1 & 351 & 25.1 & 368 & 26.3 & 180 & 12.9 \\
\hline 10 & Mlk.prd & 787 & 56.2 & 613 & 43.8 & - & - & - & - & - & - \\
\hline 11 & Oils & - & - & - & - & - & - & 569 & 40.6 & 831 & 59.4 \\
\hline
\end{tabular}

Table 3: Food Consuming Pattern the of Families $(n=1400)$

*NB: Food Groups

1. S.Food: Sea Food

2. F.W.Fish: Fresh Water Fish

3. Bf/Mut: Beef/ Mutton

4. Chicken: Chicken

5. Eggs: Eggs

6. Leg./Puls : Legume and Pulses

7. Fruits: Fruits

8. G.F.Veg.: Green Leafy Vegetables

9. Milk : Milk other than breast milk

10. Mlk.prd: Butter/Cheese/ Curd/ Yoghurt/Ghee

11. Oils: Coconut and Other Oils, Margarine

with all three nutritional problems, having p-values less than 0.05 and odds ratio more than 1 . The period of exclusive breast feeding $(\mathrm{OR}=$ 2.29; $\mathrm{P}$ value 0.041$)$ and the time of commencing complementary feeding ( $\mathrm{OR}=1.51$; $\mathrm{P}$ value 0.011 ) were also significant predictors of the nutritional status of the children (Table 4).

\section{Discussion}

The indicators of malnutrition among the children of eastern province such as the $\mathrm{Z}$ scores of height/length-for-age, weight-forheight, and weight -for -age are seen higher than the average $Z$ scores of the country. So there are higher prevalence rates of stunting, wasting, and underweight among children aged 6-36 months, in the eastern province of Sri Lanka. In comparison with the finding of National Nutrients and Micronutrients Survey-2012, the age group 6-11 months has higher percentage of wasting and the age group 12- 36 months has higher percentage of stunting in the [3] eastern province.

Monthly income, education level, and age of the mother are associated with all [3] nutritional indicators showing a p-value of less than 0.005 and odds ratio of more than 1 . Non-compliance to exclusive breast feeding, delay in commencing complementary feedings and unavailability of complementary feeding guidance are strongly associated with all types of undernutrition. For the pregnant mothers, nutritional supplementation and worm treatment during the antenatal period contribute positively towards the nutritional status of their children. There is a strong association between poor attendance to wellbaby clinic and undernutrition. The period of exclusive breast feeding also has strong association with nutritional status.

The prevalence of undernutrition in the eastern province is highly associated with the dietary habits and health practice of the mothers/ care givers. The food habit of the family in food selection, serving and frequency strongly affect the nutritional status of the children. A higher proportion of rice and similar dishes in daily food serving have considerable associations with wasting, stunting and underweight of the children. It is compulsory to educate mother/care givers using a proper nutrition counseling system.

There is a higher prevalence rate of undernutrition among children aged 6-36 months, in the eastern province of Sri Lanka. This unhealthy situation has been notified for last few years [3,7]. Poverty, illiteracy and the long lasted civil war were the obvious reasons for this [15].

According to this study, the predictors like inadequate family income, lower educational status, nuclear family type and the unavailability of complementary feeding guidance are strongly associated with undernutrition showing a p-value of less than 0.005 and higher odds ratios. And the prevalence of undernutrition in the eastern province is highly associated with the dietary habits and health practice of the mothers/ care givers, it is compulsory to educate mother/care givers using a proper nutrition counseling system.

Several frameworks have been used to describe the potential determinants of child malnutrition in the past $[6,7,16]$. Based on international literature on the causes of malnutrition and how they are interrelated, we analyzed the survey data in order to identify the current nutritional status of children aged 6-36 months, in eastern province of Sri Lanka. In this study, we also indentified the factors contributing to the current nutritional status among these children.

The complementary feeding indicators such as dietary diversity and minimum acceptable diet according to new indicators of IYCF and the inherent variables such as age, sex, birth weight and maternal height were also included. An analysis guided by the hierarchical interrelationships of potential determinants of stunting in Uganda has also considered these inherent factors as a separate entity [16].

Undernutrition is more common among the children who were born with a lower birth weight. Size at birth or birth weight has an important role in determining growth during infancy [10]. The strongest predictors recognized through this study were maternal short stature and low birth weight. Previous studies have also revealed similar results that short maternal stature was associated with both low 


\begin{tabular}{|c|c|c|c|c|}
\hline \multirow{2}{*}{ Predictors of Stunting } & \multirow{2}{*}{ OR } & \multicolumn{2}{|c|}{$95.0 \%$ C.I } & \multirow{2}{*}{ p-value } \\
\hline & & Low & Up & \\
\hline \multicolumn{5}{|l|}{ Education level of parents } \\
\hline \multirow{3}{*}{$\begin{array}{l}\text { Below Secondary School } \\
\text { Secondary School completed } \\
\text { Above Secondary School }\end{array}$} & 4.91 & 1.83 & 49.3 & .048 \\
\hline & 2.20 & .162 & 11.9 & .218 \\
\hline & 1 & & & \\
\hline \multicolumn{5}{|l|}{ Mother's/ care giver's Age } \\
\hline \multirow{3}{*}{$\begin{array}{l}\text { Below } 22 \text { years } \\
\text { Above } 35 \text { years } \\
22-35 \text { years }\end{array}$} & 1.87 & 1.48 & 1.92 & .038 \\
\hline & 2.15 & .511 & 1.77 & .527 \\
\hline & 1 & & & \\
\hline \multicolumn{5}{|l|}{ Monthly income } \\
\hline \multirow{2}{*}{$\begin{array}{l}\text { Below Rs 20000/= } \\
\text { Above Rs 20000/= }\end{array}$} & 1.48 & 1.11 & 2.01 & .011 \\
\hline & 1 & & & \\
\hline \multicolumn{5}{|l|}{ Family type } \\
\hline Nuclear Family & 1.11 & 1.03 & 1.67 & .042 \\
\hline Extended family & 1 & & & \\
\hline \multicolumn{5}{|l|}{ Iron intake during Pregnancy } \\
\hline \multirow{2}{*}{$\begin{array}{l}\text { Yes } \\
\text { No }\end{array}$} & 1 & & & \\
\hline & 1.71 & 1.45 & 2.13 & .015 \\
\hline \multicolumn{5}{|l|}{ Folate intake during Pregnancy } \\
\hline \multirow{2}{*}{$\begin{array}{l}\text { Yes } \\
\text { No }\end{array}$} & 1 & & & \\
\hline & 1.38 & 1.06 & 1.98 & .041 \\
\hline \multicolumn{5}{|l|}{ Worm Rx during Pregnancy } \\
\hline \multirow{2}{*}{$\begin{array}{l}\text { Yes } \\
\text { No }\end{array}$} & 1 & & & \\
\hline & 2.56 & 1.25 & 5.25 & .010 \\
\hline \multicolumn{5}{|l|}{ child had diarrhoea recently } \\
\hline Yes & 1.33 & 1.14 & 3.27 & .035 \\
\hline No & 1 & & & \\
\hline \multicolumn{5}{|l|}{ Low Birth Weight } \\
\hline Birth Weight below $2.5 \mathrm{~kg}$ & 1.28 & 1.03 & 3.42 & .049 \\
\hline Birth Weight abow $2.5 \mathrm{~kg}$ & 1 & & & \\
\hline \multicolumn{5}{|l|}{ Was the child given colostrums? } \\
\hline Yes & 1 & & & \\
\hline No & 1.32 & 1.18 & 1.79 & 045 \\
\hline \multicolumn{5}{|l|}{ EBF period } \\
\hline Less than 6 months & 2.29 & 1.58 & 3.87 & .041 \\
\hline 6 months & 1 & & & \\
\hline More than 6 months & 1.34 & .723 & 1.98 & .040 \\
\hline \multicolumn{5}{|l|}{ CF commencement } \\
\hline $6^{\text {th }}$ month & 1 & & & \\
\hline After $6^{\text {th }}$ month & 1.51 & 1.31 & 1.85 & .011 \\
\hline \multicolumn{5}{|l|}{ Regular visit to children clinic } \\
\hline Yes & 1 & & & \\
\hline No & 1.52 & 1.33 & 3.16 & .041 \\
\hline Getting advices on CF from & & & & \\
\hline Heath care personnel & 1 & & & \\
\hline others & 1.41 & 1.24 & 2.04 & 0.041 \\
\hline
\end{tabular}

Table 4: Odds Ratios of risk factors for stunting among the children aged 6-36 months in eastern province, Sri Lanka $(n=1400)$.

birth weight and stunting in the offspring [12,17]. According to our study, there is association of low birth weight with all three nutritional indicators $(\mathrm{p}<0.05$ and $\mathrm{OR}>1)[18,19]$.

Children from the poorest families carry a significantly higher risk of malnutrition reflecting the inadequate access to food or household food insecurity among other factors. Even stronger associations have been detected between socio economic deprivation and stunting in the study by Hong et al., after adjusting for possible confounding factors [20]. Similar findings have been reported in other studies about the high prevalence of stunting in marginalized groups [21]. Availability of sanitation facilities is associated with a lower prevalence rate of undernutrition. This is compatible with the findings of other investigators [20]. Lower incidence of infections and higher socio economic status could be the likely reasons for this finding.

More and more children tend to get stunted as they grow older, which is depicted in the association between age and stunting. This is similar to the findings of Schmidt et al. in West Java, and points towards the strong role of environmental factors in stunting [22]. The present analysis included feeding practices as predictor variables. In the study by Brennan et al., the certain feeding practices such as not discarding colostrums, not using feeding bottle, and timely complementary feeding were associated with reduced stunting [19]. However our analysis detected associations between feeding practices such as exclusive breast feeding and complementary feeding with wasting stunting and underweight in Sri Lankan children.

The children who had frequent diarrhea in last two weeks more often show declines in their nutritional status, according to this study. Although diseases are an immediate cause for undernutrition, according to the UNICEF conceptual framework, the present analysis shows significant association between diarrheal diseases and wasting in Sri Lanka. This is similar to the findings of Schmidt et al. in Java where having fever predicted weight-for-age but not height-forage [21]. This contradicts the findings of most other investigators who have demonstrated a statistically highly significant association between diarrhea and stunting [23,24]. Additional information such as frequency of attacks may explain this discrepancy. Our study too reveals that wasting $(\mathrm{p}=0.00$ and $\mathrm{OR}=2.24)$ and stunting $(\mathrm{p}=0.03$ and $\mathrm{OR}=1.35$ ) have strong associations with frequent diarrhea.

Low maternal education in the present study was significant in the analysis. This corporate with the findings of Wamani et al. where maternal education was the only significant predictor in the adjusted analysis [25]. Several previous studies had also demonstrated positive associations between low maternal education and stunting $[11,26]$. However according to a study in Bolivia, maternal education imparts its effect on malnutrition largely through other socio economic factors [8]. There is evidence from Indonesia and Bangladesh that both maternal and paternal education have a protective effect on stunting [27].

Our analysis was restricted to 6-36 months age group simply because identifying predictors relevant to this group would be more useful for interventions targeting this age. Evidence shows that interventions for stunting after this age window are less effective, according to available evidence [8]. The major limitation of this analysis is the cross sectional nature of survey data, and due cautions should be taken when interpreting results because stunting is a consequence of long term exposure to several variables. Therefore we recommend further, preferably cohort studies on stunting including all the variables with programmatic relevance.

Since there is an extremely large gap between the undernutrition rates of estate and other sectors, addressing the inequalities of this sector in policies and programmes geared at improving health and nutrition is essential. Socio economic factors have a big impact on undernutrition which requires effective inter-sectoral coordination to tackle this issue.

\section{Conclusion}

The reasons for the failure of the current program of the country are poor knowledge and poor economy of the people. Making awareness 
Citation: Sujendran S, Senarath U, Joseph J (2015) Prevalence of Stunting among Children Aged 6 to 36 Months, in the Eastern Province of Sri Lanka. J Nutr Disorders Ther 5: 154. doi:10.4172/2161- 0509.1000154

among public is the major recommendation. The new knowledge existing from this study is the evidence for the effects of current infant and young child feeding practices. This knowledge will be useful in the Maternal and Child health programmes to improve child nutrition and thereby growth and survival of children. A healthy younger population is a positive index for future healthy nation. As a country with a healthy people, we can minimize health care expenditures as well.

\section{Acknowledgement}

Financial assistance given by Higher Education for the Twenty first Century (HETC Grant No: HETC/CMB/QIGW3/MED/TOR-04) of Sri Lanka is acknowledged. We would like to thank Regional Directors of Health Services and their staff of Batticaloa and Kalmunai health districts.

\section{Reference}

1. World Health Organization (2008) Infants and young children feeding counseling, an integrated, Participant's manual, Geneva.

2. Park PK (2009) Textbook of preventive and social medicine. (21stedn), Banarsidas Bhanot Publishers, Jabalpur.

3. Department of Census and Statistics \& Ministry of Healthcare and Nutrition of Sri Lanka. Sri Lanka Demographic and Health Survey-2006-07.

4. Jayatissa R, Hossain SMM (2010) Nutrition and Food Security Assessment in Sri Lanka: Nutrition and Food Security Survey. Colombo: Medical Research Institute and UNICEF.

5. Ministry of Healthcare and Nutrition and UNICEF (2008) Sri Lanka complementary feeding study - Factors associated with complementary feeding in Sri Lanka. Colombo: Ministry of Healthcare and Nutrition and UNICEF.

6. Black RE, Allen LH, Bhutta ZA, Caulfield LE, Ezzati M, et al. (2008) Maternal and child undernutrition: global and regional exposures and health consequences. Lancet 371: 243-260.

7. UNICEF (1990) Strategy for improved nutrition of children and women in developing countries. New York.

8. Bhutta ZA, Ahmed T, Black RE, Cousens S, Dewey K, et al. (2008) What works? Interventions for maternal and child undernutrition and survival. Lancet 371: 417-440.

9. Schroeder DG, Martorell R, Flores R (1999) Infant and child growth and fatness and fat distribution in Guatemalan adults. Am J Epidemiol 149: 177-185

10. Arifeen SE, Black RE, Caulfield LE, Antelman G, Baqui AH (2001) Determinants of infant growth in the slums of Dhaka: size and maturity at birth, breastfeeding and morbidity. Eur J Clin Nutr 55: 167-178.

11. Baig-Ansari N, Rahbar MH, Bhutta ZA, Badruddin SH (2006) Child's gender and household food insecurity are associated with stunting among young Pakistani children residing in urban squatter settlements. Food Nutrtrition Bulletin 27: 114-127.

12. Ferreira HS, Moura FA, Cabral CRJR, Florencio TM, Vieira RC, et al. (2009) Short stature of mothers from an area endemic for undernutrition is associated with obesity, hypertension and stunted children: a population-based study in the semi-arid region of Alagoas, Northeast Brazil. Br J Nutr 101: 1239-1245.

13. Pramod Singh GC, Nair M, Grubesic RB, Connell FA (2009) Factors associated with underweight and stunting among children in rural Terai of eastern Nepal. Asia Pac J Public Health 21: 144-152.

14. Medical Research Institute of The Ministry of Helathcare and Nutrition (2006) Child Undernutrition in Sri Lanka: Causal Analysis. Colombo: Ministry of Helathcare and Nutrition.

15. Donner A, Klar N (2000) Design and analysis of cluster randomization trials in health research, (1stedn) Arnold Publishers, London.

16. Wamani H, Astrom AN, Peterson S, Tumwine JK, Tylleskar T (2006) Predictors of poor anthropometric status among children under 2 years of age in rural Uganda. Public Health Nutr 9: 320-326.

17. Subramanian SV, Ackerson LK, Davey Smith G, John NA (2009) Association of maternal height with child mortality, anthropometric failure, and anemia in India. JAMA 301: 1691-1701.

18. Hong R, Banta JE, Betancourt JA (2006) Relationship between household wealth inequality and chronic childhood under-nutrition in Bangladesh. Int $J$ Equity Health 5: 15.

19. Larrea C, Kawachi I (2005) Does economic inequality affect child malnutrition? The case of Ecuador, Soc Sci Med 60: 165-178

20. Checkley W, Gilman RH, Black RE, Epstein LD, Cabrera L, et al. (2004) Effect of water and sanitation on childhood health in a poor Peruvian peri-urban community. Lancet 363: 112-118.

21. Brennan L, Mcdonald J, Shlomowitz R (2004) Infant feeding practices and chronic child malnutrition in the Indian states of Karnataka and Uttar Pradesh. Econ Hum Biol 2: 139-158.

22. Schmidt MK, Muslimatun S, West CE, Schultink W, Gross R, et al. (2002) Nutritional status and linear growth of Indonesian infants in west java are determined more by prenatal environment than by postnatal factors. J Nutr 132: $2202-2207$

23. Adair LS, Guilkey DK (1997) Age-specific determinants of stunting in Filipino children. Journal of Nutrition 127: 314-320.

24. Checkley W, Buckley G, Gilman RH, Assis AM, Guerrant RL, et al. (2008) Multi-country analysis of the effects of diarrhoea on childhood stunting. Int J Epidemiol 37: 816-830.

25. Wamani H, Tylleskar T, Astrom AN, Tumwine JK, Peterson S (2004) Mothers' education but not fathers' education, household assets or land ownership is the best predictor of child health inequalities in rural Uganda. Int $\mathrm{J}$ Equity Health 3. 9

26. Shah SM, Selwyn BJ, Luby S, Merchant A, Bano R (2003) Prevalence and correlates of stunting among children in rural Pakistan. Pediatr Int 45: 49-53.

27. Semba RD, de Pee S, Sun K, Sari M, Akhter N, et al. (2008) Effect of parental formal education on risk of child stunting in Indonesia and Bangladesh: a crosssectional study. Lancet 371 : $322-328$ 